\title{
Maternal obesity as a risk factor for caesarean section: a case control study
}

\author{
Bindu Nambisan*, Sreekumary Radha
}

\begin{abstract}
Department of Obstetrics and Gynaecology, Government Medical College, Trivandrum, Kerala, India
\end{abstract}
Received: 29 August 2016

Accepted: 28 September 2016

\section{*Correspondence:}

Dr. Bindu Nambisan,

E-mail: bindu.nambisan1971@gmail.com

Copyright: ( ) the author(s), publisher and licensee Medip Academy. This is an open-access article distributed under the terms of the Creative Commons Attribution Non-Commercial License, which permits unrestricted non-commercial use, distribution, and reproduction in any medium, provided the original work is properly cited.

\begin{abstract}
Background: Obesity is the most common nutritional disorder in the affluent, industrialized and developed world. Worldwide it exists at a prevalence of about 20\% when Body Mass Index of more than 30 was considered. According to the current Asian Guidelines a BMI > 25 in pregnancy is considered to be obese. Maternal obesity is on the rise and so are the maternal and perinatal complications. The objective of the study was to find out if maternal obesity was an independent risk factor for Caesarean section. Over the years, there have been innumerable accounts of obstetricians coming under the media and public ire, blaming them for the rising Caesarean section rates. This study was undertaken to know if changing socio-demographic characteristics have also contributed to the rise.

Methods: This was a case control study. In order to have uniformity amongst 'cases' and 'controls', in terms of age group and other co morbidities, only primigravida were included in this study. It was conducted in, a tertiary reference centre in Thiruvananthapuram under government sector which mostly caters to low and medium socioeconomic groups. The 'cases' were defined as 'all subjects who underwent Caesarean section' and the 'controls' were defined as 'all those who underwent vaginal delivery'. Data were collected, after informed consent, by going through patient records and interview method using a questionnaire. Sample size was statistically calculated using data conducted from a pilot study done, using few subjects. Current Asian guidelines for obesity were used with BMI $>25$ being considered as obese and weight of the pregnant women in the very first visit was considered, if in the first trimester. Literature search has shown very few studies that were done considering current Asian guidelines.

Results: This study conclusively proved that maternal obesity is an independent risk factor for Caesarean section. The odds of ending up in caesarean section are about 2.8 times more amongst the obese than the non-obese. When the overweight and obese were considered together, the odds of ending up in Caesarean section was 2.3 times more.

Conclusions: Since obesity is an independent risk factor for Caesarean section, it is imperative that weight control measures are initiated from adolescence. Preconceptional counseling regarding weight control is also important to prevent complications of obesity in reproductive years.
\end{abstract}

Keywords: Body mass index, Caesarean section, Obesity, Overweight, Primigravida

\section{INTRODUCTION}

Obesity is the most common nutritional disorder in the affluent industrialized and developed world. ${ }^{1}$ Body mass index is nowadays accepted as a reasonable measure of overweight and underweight. Worldwide obesity, as defined by a BMI $>30$, exists at a prevalence of $15-20 \%$ and accounts for substantial amount of health care costs.
In India no data regarding the magnitude of obesity in pregnancy is available. High pre-pregnancy BMI is associated with adverse maternal outcomes like early miscarriage, PIH, preeclampsia, gestational Diabetes mellitus, thrombo-embolic phenomena, prolonged labour and rising C.S rates. ${ }^{2-4}$ Additional complications include intra operative and post-operative complications, and difficulties related to anaesthesia management. 
The aim of conducting this study was to find out the magnitude of obesity related complications (as per the changed guidelines for obesity in the Asian population) with emphasis on whether it contributes to rising Caesarean section rates. Kerala has a very high rate of institutional delivery, thereby allowing us to generalise the findings, and since the rate of obesity is high, it would help us to confirm or negate this hypothesis.

Rising Caesarean section rates has been a long time concern globally and efforts need to be taken to stall this trend. BMI (weight in $\mathrm{kg}$ per height in $\mathrm{m}^{2}$ ) of more than 30 is globally accepted as obesity. The body fat distribution is considered to be higher in Asians as compared to Europeans. Even though the prevalence of obesity was lower amongst Asians, the rate of obesity related diseases was higher. ${ }^{5} \mathrm{WHO}$ in collaboration with International Association for study of obesity in Pregnancy have come out with different ranges.

For the Asian population, BMI

$$
\begin{array}{ll}
<18.5 & - \text { Underweight } \\
18.5 \leq 22.9 & - \text { Normal } \\
23 \leq 24.9 & \text { - Overweight } \\
25 & \text { - Obese }
\end{array}
$$

Studies have proven that pre-pregnancy BMI is more associated with maternal and perinatal outcome than weight gain in pregnancy. Researches have shown that Indians suffer from abdominal obesity compared to people in the West whose bodies are uniformly obese. This body composition puts Indian in the high risk zone for diabetes and hypertension.

This case control study was conducted in a tertiary level referral centre in public sector in Kerala, South India for a period of 6 months. Since Kerala has a very high rate institutional delivery nearing around $99 \%$ and because of high awareness amongst the women, history taken via questionnaire method and interviews could be relied upon. A detailed questionnaire that included sociodemographic factors, anthropometric measurements, current pregnancy details as regards to various comorbidities and any significant past or family history was collected. Delivery details were included in detail in this study. The details of the baby like birth weight and perinatal complications if any were also noted down.

\section{METHODS}

All primigravida with booking in the first trimester were included in the study. Those who underwent CS were designated as cases and those who underwent vaginal delivery were the control group. Around 245 cases and 298 controls were studied. Pregnant woman with late booking and multiple gestations were excluded from the study

\section{Sample size}

This was calculated using the formula

$\mathrm{n}=\frac{\left(\mathrm{Z}_{\alpha}+\mathrm{Z}_{2 \beta}\right)^{2}\left[\mathrm{P}_{1}\left(1-\mathrm{P}_{1}\right)+\mathrm{P}_{2}\left(1-\mathrm{P}_{2}\right)\right]}{\left(\mathrm{P}_{1}-\mathrm{P}_{2}\right)^{2}}$

Where,

$\alpha=$ Type I error (fixed at $5 \%$ level)

$1-\beta=$ Power(fixed at $80 \%$ level)

$\mathrm{P}_{1}=$ Prevalence of obesity in LSCS group

$\mathrm{P}_{2}=$ Prevalence of obesity in Vag del group

Values of P1and P2 were obtained from pilot study as 0.26 and 0.16 respectively. Based on these values $n$ is fixed as 245 . Hence 245 cases and 245 controls were included in the study.

\section{RESULTS}

\section{Age distribution}

In both the cases as well as controls the maximum number of cases belonged to the age group range of 2029 yrs. There were approximately $80 \%$ women in this age group amongst both cases and controls (Table 1) (Table 2) (Figure 1).

Table 1: Age distribution among sample.

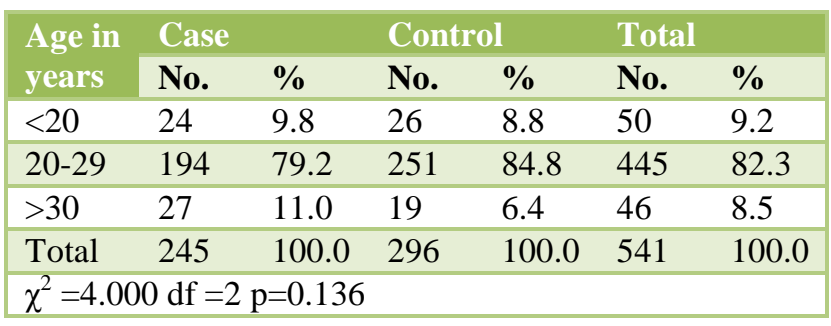

Table 2: Mean and Sd of the sample.

\begin{tabular}{|lll|}
\hline & $\begin{array}{l}\text { Age in years } \\
\text { Case }\end{array}$ & Control \\
\hline $\mathrm{N}$ & 245 & 296 \\
\hline Mean & 24.19 & 23.41 \\
\hline $\mathrm{Sd}$ & 4.452 & 3.420 \\
\hline Minimum & 18 & 18 \\
\hline Maximum & 43 & 35 \\
\hline
\end{tabular}

\section{Socioeconomic classification}

This was assessed as per the modified Kuppuswamy classification for urban areas taking into consideration combined family income, educational status and occupational levels. Majority of cases belonged to the 
lower middle income group amongst both cases as well as controls. Both the cases and controls were comparable in terms of distribution. The next major category was the upper lower and the upper middle groups. Both the cases and controls were comparable in all the categories (Table 3) (Figure 2).

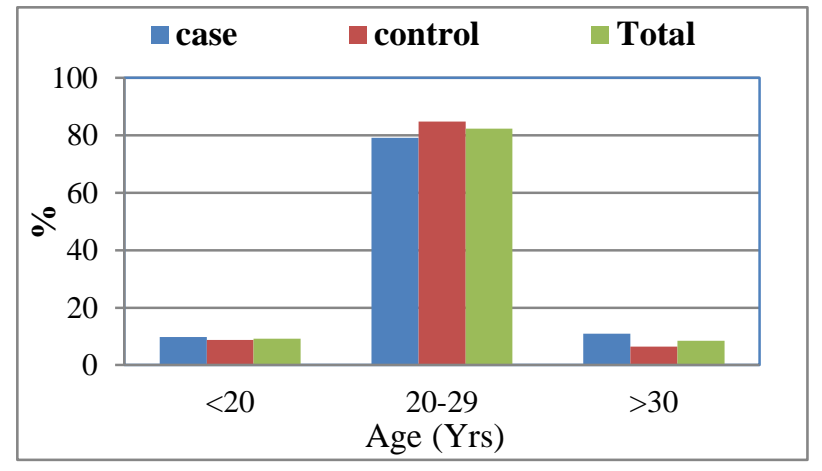

Figure 1: Age distribution in the sample.

Table 3: Socio Economic Scale (SES).

\begin{tabular}{|lllllll|}
\hline \multirow{2}{*}{ SES } & \multicolumn{2}{c}{ Case } & \multicolumn{2}{c}{ Control } & \multicolumn{2}{l}{ Total } \\
\cline { 2 - 7 } & No. & $\%$ & No. & $\%$ & No. & $\%$ \\
\hline $\begin{array}{l}\text { Upper and } \\
\text { upper middle }\end{array}$ & 41 & 16.7 & 59 & 19.9 & 100 & 18.5 \\
\hline $\begin{array}{l}\text { Lower } \\
\text { middle }\end{array}$ & 145 & 59.2 & 179 & 60.5 & 324 & 59.9 \\
\hline Upper lower & 59 & 24.1 & 58 & 19.6 & 117 & 21.6 \\
\hline Total & 245 & 100.0 & 296 & 100.0 & 541 & 100.0 \\
\hline$\chi^{2}=2.027 \mathrm{df}=2 \mathrm{p}=0.363$ & & & & \\
\hline
\end{tabular}

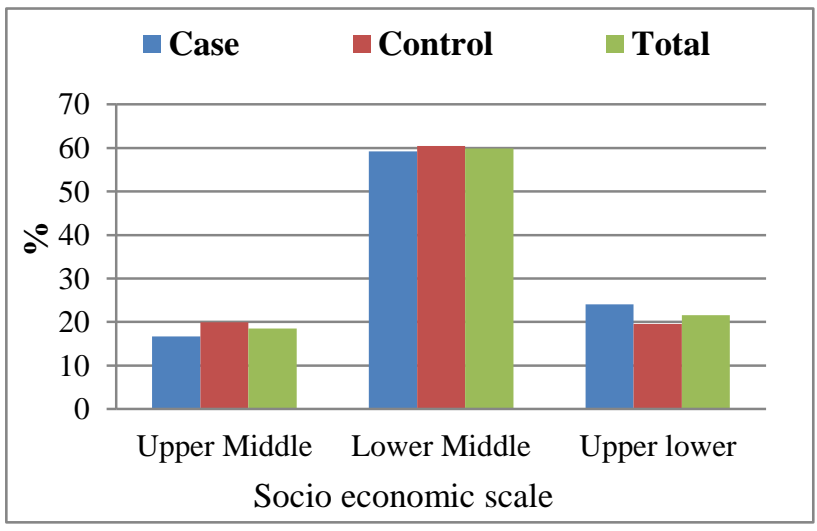

Figure 2: Classification based on SES.

\section{Classification as per gestational age}

All the subjects beyond 37 completed weeks of gestation were considered to be of term gestation. There were 196 patients in the cases group contributing to about $80 \%$ of the total cases and 247 patients in the control group contributing to about $83 \%$ of total. On an average $81 \%$ were term gestation of the total subjects. $7 \%$ of subjects were beyond 40 weeks described as being past date, and $11 \%$ of subjects were between 34 and 37 weeks of gestation. Mean gestational age for cases was 37.82 and sd was 1.31. Minimum gestational age was 33 weeks and maximum was 41 weeks. Mean gestational age for control was 38.09 and sd was 1.307. Minimum gestational age was 34 weeks and maximum was 41 weeks (Table 4) (Table 5).

Table 4: Distribution as per gestational age.

\begin{tabular}{|lllllll|}
\hline $\begin{array}{l}\text { GA } \\
\text { in } \\
\text { weeks }\end{array}$ & No. & $\%$ & No. & $\%$ & No. & $\%$ \\
\hline$<34$ & 2 & 0.8 & 0 & 0.0 & 2 & 0.4 \\
\hline $34-37$ & 32 & 13.1 & 26 & 8.8 & 58 & 10.7 \\
\hline $37-40$ & 196 & 80.0 & 247 & 83.4 & 443 & 81.9 \\
\hline$>40$ & 15 & 6.1 & 23 & 7.8 & 38 & 7.0 \\
\hline Total & 245 & 100.0 & 296 & 100.0 & 541 & 100.0 \\
\hline$\chi^{2}=3.849 \mathrm{df}=2 \mathrm{p}=0.146$ \\
\hline \multicolumn{7}{|l}{} \\
\hline
\end{tabular}

Table 5: Mean and Sd of gestational age (GA).

\begin{tabular}{|lll|}
\hline Gestational age $($ weeks) & \\
\hline Number & Case $(245)$ & Control (296) \\
\hline Mean & 37.82 & 38.09 \\
\hline Sd & 1.318 & 1.307 \\
\hline Minimum & 33 & 34 \\
\hline Maximum & 41 & 41 \\
\hline
\end{tabular}

\section{Body mass index}

In this study as per Asian guidelines BMI $>25$ is taken as being obese and that between 23 and 25 is taken as being overweight (Table 6) (Table 7) (Figure 3).

Table 6: Distribution of BMI.

\begin{tabular}{|lllllll|}
\hline & \multicolumn{2}{c}{ Case } & \multicolumn{3}{c|}{ Control } & \multicolumn{2}{c|}{ Total } \\
& No. & $\%$ & No. & $\%$ & No. & $\%$ \\
\hline $\begin{array}{l}<18.5 \\
\text { (underweight) }\end{array}$ & 39 & 15.9 & 58 & 19.6 & 97 & 17.9 \\
\hline $\begin{array}{l}18.5-22.9 \\
\text { (normal) }\end{array}$ & 89 & 36.3 & 156 & 52.7 & 245 & 45.3 \\
\hline $\begin{array}{l}\text { 23-24.9 } \\
\text { (overweight) }\end{array}$ & 42 & 17.1 & 42 & 14.2 & 84 & 15.5 \\
\hline$>25$ (obese) & 75 & 30.6 & 40 & 13.5 & 115 & 21.3 \\
\hline Total & 245 & 100.0 & 296 & 100.0 & 541 & 100.0 \\
\hline
\end{tabular}

Table 7: Distribution of BMI consolidated.

\begin{tabular}{|c|c|c|c|c|c|c|}
\hline \multirow{2}{*}{ BMI } & \multicolumn{2}{|c|}{ Case } & \multicolumn{2}{|c|}{ Control } & \multicolumn{2}{|c|}{ Total } \\
\hline & $\mathbf{N}$ & $\%$ & $\mathbf{N}$ & $\%$ & $\mathbf{N}$ & $\%$ \\
\hline $\begin{array}{l}\geq 23 \\
\text { (ow+obese) }\end{array}$ & 117 & 47.8 & 82 & 27.7 & 199 & 36.8 \\
\hline $\begin{array}{l}<23 \\
\text { (uw+normal) }\end{array}$ & 128 & 52.2 & 214 & 72.3 & 342 & 63.2 \\
\hline Total & 245 & 100.0 & 296 & 100.0 & 541 & 100.0 \\
\hline $\begin{array}{l}\chi^{2}=23.180 \mathrm{~d} \\
3.410\end{array}$ & 1 & $001 \mathrm{OI}$ & -238 & $95 \%$ & {$[=1.6$} & \\
\hline
\end{tabular}




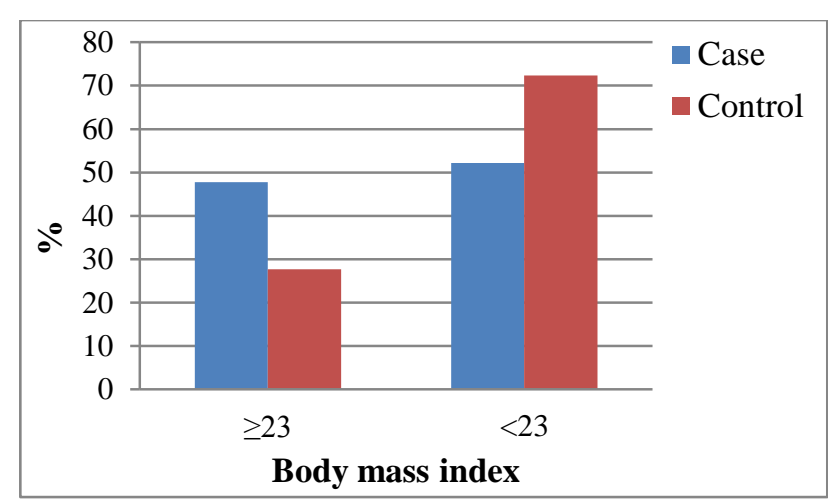

Figure 3: Distribution of overweight and Obese amongst case and control.

It is proven that there is a statistically significant increase in Caesarean section amongst the women who are overweight and obese than those with normal or underweight. The Odds of ending up with Caesarean is 2.3 times more amongst the overweight and obese groups (Table 8).

Table 8: Mean and Sd of BMI.

\begin{tabular}{|lll|}
\hline & BMI & \\
\hline Number & Case (245) & Control (296) \\
\hline Mean & 22.97 & 21.29 \\
\hline Sd & 4.493 & 3.644 \\
\hline Minimum & 13 & 13 \\
\hline Maximum & 40 & 39 \\
\hline
\end{tabular}

Table 9: Obesity distribution in the sample.

\begin{tabular}{|lllllll|}
\hline & Case & \multicolumn{4}{c|}{ Control } & Total \\
& $\mathbf{N}$ & $\mathbf{\%}$ & $\mathbf{N}$ & $\mathbf{\%}$ & $\mathbf{N}$ & $\%$ \\
\hline Obese & 75 & 30.6 & 40 & 13.5 & 115 & 21.3 \\
\hline $\begin{array}{l}\text { Non } \\
\text { obese }\end{array}$ & 170 & 69.4 & 256 & 86.5 & 426 & 78.7 \\
\hline Total & 245 & 100.0 & 296 & 100.0 & 541 & 100.0 \\
\hline $\begin{array}{l}\chi^{2}=23.414 \\
-4.340\end{array}$ \\
\hline
\end{tabular}

Further the obese and the non-obese groups were compared. There is a statistically significant increase in the risk of Caesarean section than in women with nonobese, the odds of risk being 2.8 times more (Table 9) (Figure 4).

\section{Maternal co morbidities}

Maternal co morbidities such as hypertensive disorders of pregnancy, gestational diabetes, anaemia, thyroid disorders, congenital or acquired heart disease and presence of vaginal candidiasis and history of urinary tract infections during pregnancy were also noted as they were also possible contributors to Caesarean section.

\section{Delivery details}

Details regarding whether it was a spontaneous onset of labour or whether labour was induced either using oxytocics or prostaglandins was also noted (Table 10).

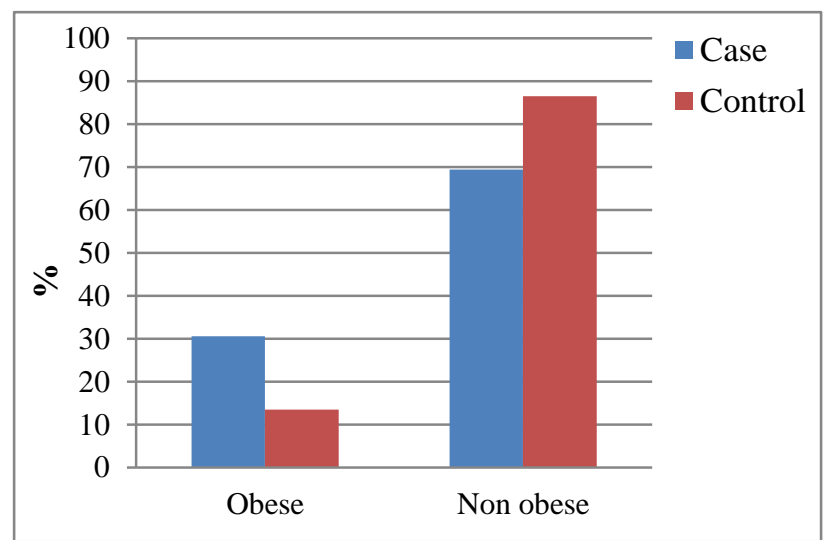

Figure 4: Distribution of obesity amongst cases and controls.

Table 10: Nature of labour.

\begin{tabular}{|lllllll|}
\hline Nature of & \multicolumn{2}{c}{ Case } & \multicolumn{2}{c}{ Control } & Total \\
labour & $\mathbf{N}$ & $\mathbf{\%}$ & $\mathbf{N}$ & $\mathbf{\%}$ & $\mathbf{N}$ & $\mathbf{\%}$ \\
\hline Induced & 149 & 60.8 & 116 & 39.2 & 265 & 49.0 \\
\hline Spontaneous & 96 & 39.2 & 180 & 60.8 & 276 & 51.0 \\
\hline Total & 245 & 100.0 & 296 & 100.0 & 541 & 100.0 \\
\hline $\begin{array}{l}\chi^{2}=25.090, \mathrm{df}=1, \mathrm{p}<0.001, \mathrm{OR}=2.408,95 \% \\
1.703-3.407\end{array}$ & & & $\mathrm{CI}=$ \\
\hline
\end{tabular}

Induction labour was significantly more in the case group $(60.8 \%)$ than the control group $(39.2 \%)$. It may be interpreted that the chances of having a Caesarean section is 2.4 times more amongst those who are induced than those having spontaneous onset of labour. Also it was noted that there was a significant increase in emergency C.S amongst the overweight and the obese groups. Failed induction followed by fetal distress topped the list of indications for $\mathrm{CS}$ in cases. The other indications were protracted active phase and malpresentations.

\section{Perinatal complications}

Incidence of perinatal complications like still birth, macrosomia and preterm births were also noted. Perinatal complications were significantly more in the case group $(16.3 \%)$ than the control group $(8.4 \%)$.

Using logistic regression the different variables were found to have significant association with Caesarean section .These include obesity, PIH on one or more drugs, presence of thyroid dysfunction, vaginal candidiasis, and induced labour (Table 11). 


\section{DISCUSSION}

This study conclusively proves that obesity is a significant risk factor. At the same time several other risk factors that proved to be significant include women who had gestational hypertension and who were on multiple antihypertensive drugs, presence of vaginal candidiasis, history of urinary tract infection in pregnancy, as well as those with thyroid dysfunction. These findings are in concordance with several other studies which have shown that compared to women with normal BMI, obese pregnant women had higher incidence of CS.

It is also a well-known fact, that thin and malnourished mothers have an increased risk of adverse perinatal outcome. But this study highlights that the other end of the spectrum is also not very encouraging. Economies in transition like India have double burden of tackling malnutrition as well as over nutrition. ${ }^{6}$

Table 11: Logistic regression.

\begin{tabular}{|c|c|c|c|c|c|c|c|}
\hline Variabl & in the Equation & B & S.E. & Wald & df & Sig. & $\operatorname{Exp}(B)$ \\
\hline \multirow{8}{*}{ Step $1^{\mathrm{a}}$} & Obese & 0.620 & 0.242 & 6.582 & 1 & 0.010 & 1.860 \\
\hline & Drugs & 0.877 & 0.253 & 12.011 & 1 & 0.001 & 2.404 \\
\hline & UTI & 0.460 & 0.218 & 4.433 & 1 & 0.035 & 1.583 \\
\hline & Thyroid dysfunction & 0.549 & 0.355 & 2.387 & 1 & 0.122 & 1.731 \\
\hline & Vaginal candidiasis & 0.885 & 0.254 & 12.126 & 1 & 0.000 & 2.423 \\
\hline & Induced labour & 0.719 & 0.192 & 13.968 & 1 & 0.000 & 2.052 \\
\hline & Complications perinatal & 0.776 & 0.306 & 6.436 & 1 & 0.011 & 2.173 \\
\hline & Constant & 4.344 & 0.644 & 45.533 & 1 & 0.000 & 0.013 \\
\hline
\end{tabular}

In a study conducted in Nalgonda, Andhra Pradesh titled 'High BMI in Pregnancy, its effects on maternal and foetal outcome' by Sujatha VV et al which was published in 2012 showed that following outcomes were significantly high in obese pregnant women, i.e. gestational diabetes, preeclampsia, macrosomia, induction of labour, caesarean sections (OR 3.45) and infections. The authors concluded that it is pertinent to identify women at risk of gestational diabetes as this increases the risk of hypertensive disorders of pregnancy, macrosomia of the infant and predisposes the women to a higher risk of developing diabetes in later life. Active strategies for weight control and life style advice after delivery with regular follow up are needed for the management of these women. The incidence of pre-term labor was thought to be high probably because of early interventions due to preeclampsia. They also suggested that it may be possible that uterine contractility may be suboptimal in obese women. There was an increased incidence of post-partum hemorrhage and infections in women with high BMI.

Obese patients have been found to have difficulty completing the second stage of labour secondary to soft tissue dystocia, and operative vaginal delivery was needed. ${ }^{7,8}$ They were also found to have higher frequency of arrest of dilatation and ineffective uterine contractility. ${ }^{9,10}$ It is believed that the presence of excess intra-abdominal adipose tissue itself could mechanically obstruct the progression of labour, contributing to failure to progress. If progress of labour is mechanically obstructed, this could, over time compromise fetoplacental circulation and cause fetal distress. The obese women theoretically were postulated to take more time to reach the optimal tissue oxytocin levels due to their larger body volume. Increased risk of caesarean delivery for failure to progress could also be the consequence of difficult abdominal and vaginal examination of obese women in labour. Without accurate monitoring of progression in labour, operative delivery risk was likely to increase. ${ }^{1-3,5}$

As obesity is considered to be a modifiable risk factor, preconception counselling and creating awareness regarding health risks associated with overweight and obesity should be encouraged. ${ }^{10}$

Obstructive sleep apnoea, commonly associated with obesity, increases blood pressure during obstructive periods and this has been also shown in pre-eclamptic obese mothers. ${ }^{11}$

The increased incidences of in utero fetal deaths in obese women were most probably due to placental dysfunction related to obesity itself. It is postulated that the hyperlipidaemia of obesity may reduce prostacycline secretion and enhance peroxidase production, resulting in vasoconstriction and platelet aggregation and thus affecting placental perfusion. ${ }^{12}$ 


\section{Policy implications}

- Interventions are needed aimed in targeting adolescent population and counselling those regarding adverse problems associated with obesity through school and community programs.

- Promote pre-conceptional counselling regarding weight control and weight reduction to women approaching hospital for other reasons like primary infertility, menstrual problems, PCOD etc.

- Coverage through media regarding adverse maternal and foetal problems in obese to get the message across larger section of people.

- Stringent anti-obesity measures need to be implemented in women to prevent the complications of obesity in reproductive years.

- In morbidly obese women where nutritional education, behavior modification, drug treatment and dieting have not been successful in reducing weight, a recent meta-analysis has shown that bariatric surgery is more effective than non-surgical treatment for weight loss in women with BMI > 40 and that bariatric surgery done preconceptionally is not associated with adverse perinatal outcome although the study showed high cesarean rate and an increased risk of anemia

\section{Limitations of this study}

The ideal time for baseline height and weight of a woman is before pregnancy or in early gestation. Most of the researchers have relied on the woman's recall of her prepregnancy weight, the reliability and standardization of which is very doubtful. In this study the height and weight of women were recorded in early pregnancy that is during the first antenatal visit in the first trimester. Still value recorded in pregnancy remains an approximation of the pre-pregnancy weight, and therefore subject to bias. However an even distribution of the weeks of antenatal visit among women helps minimize selection bias. Also since in the first trimester there is not much gain in weight compared to the other two trimesters values would be near approximate. Since even the referred cases with regular antenatal visits were included in the study there remains an underlying problem of instruments like the weighing machine being standardised.

\section{CONCLUSION}

This case control study has proven that maternal obesity is a significant risk factor for Caesarean section Analysis of data shows that the ODDS of ending up with Caesarean is 2.8 times more amongst obese groups than the non-obese.

The study subjects in this study belong to middle and low socioeconomic groups. It can be reasonably assumed that the chance of obesity is probably much higher in the upper socioeconomic scale and thereby the chances of ending up in CS may be much higher in this group.

Since Obesity rate has rapidly increased in the general population and in women of childbearing age, it would be ideal to promote pre-conceptional counselling regarding weight control and weight reduction to prevent the complications of obesity in reproductive years.

Funding: No funding sources

Conflict of interest: None declared

Ethical approval: The study was approved by the Institutional Ethics Committee

\section{REFERENCES}

1. Bhattacharya S, Campbell DM, Liston WA, Bhattacharya S. Effects of body mass index on pregnancy outcomes in nulliparous women delivering singleton babies. BMC Public Health 2007;7:168.

2. Jaleel R. Impact of Maternal Obesity on Pregnancy Outcome, Journal of Surgery Pakistan (International). 2009;14(1).

3. Sae-Kyung Choi, In-Yang Park, Jong-chul Shin. The effects of pre-pregnancy body mass index and gestational weight gain on perinatal outcomes in Korean women: a retrospective cohort study, Reproductive Biology and Endocrinology. 2011;9:6.

4. Islam A, Khan NA, Ehsan A. Complications of raised BMI in pregnancy. Professor Med J Sep. 2010;17(3):498-504.

5. Choo V: WHO reassesses appropriate body mass index for Asian populations. Lancet. 220,360:235.

6. Guelinckx I, Devlieger R, Beckers K, Vansant G. Maternal obesity: pregnancy complications, gestational weight gain and nutrition. Obes Rev. 2008;9:140-50.

7. Mandal D, Mandal S, Rakshit A. Maternal obesity and pregnancy outcome: a prospective analysis. Med J. 2011;59:15-8.

8. Satpathy KH, Fleming A, Frey D, Barssom M, Satpathy C, Fossen K. Maternal obesity and pregnancy. Postgraduate Medicine 2008;120:E01-09.

9. Andreasen KR, Andresen ML, Schantz AL. Obesity and pregnancy. Acta Obstet Gynecol Scand 2005;83:102224.

10. Verdiales M, Pacheco C, Cohen WR. The effect of maternal obesity on the course of labor. J of Perinatal Med. 2009;37:651-5.

11. Cedergnen MI. Non-elective cesarean delivery due to in effective uterine contractility or due to obstructed labor in relation to maternal body mass index. Er J of Obst and Gynec and Reprod Biol. 2009;145:163-6.

12. Nohr EA, Bech BH, Davies MJ, Frydenberg M, Henriksen TB, Olsen J. Prepregnancy obesity and fetal death. Obstet Gynecol. 2005;106:250-9.

13. Casto LC. Avina RL. Maternal obesity and pregnancy outcomes. Current Opinion in Obstetrics and Gynecology. 2002;14:601-06.

Cite this article as: Nambisan B, Sreekumary R. Maternal obesity as a risk factor for caesarean section: a case control study. Int J Reprod Contracept Obstet Gynecol 2016;5:3909-14. 